\title{
Gastrointestinal Complications of Ferrous Sulfate in Pregnant Women: A Randomized Double-Blind Placebo-Controlled Trial
}

\author{
Esmat Jafarbegloo ${ }^{1}$; Hoda Ahmari Tehran ${ }^{2}$; Tahmineh Dadkhah Tehrani ${ }^{1, *}$ \\ ${ }^{1}$ School of Nursing and Midwifery, Health Care Research Center, Qom University of Medical Sciences, Qom, IR Iran \\ 2 PhD Student in Medical Education, Department of Medical Education, Tehran University of Medical Sciences, Tehran, IR Iran \\ *Corresponding Author: Tahmineh Dadkhah Tehrani, School of Nursing and Midwifery, Health Care Research Center, Qom University of Medical Sciences, Qom, IR Iran. Tel: \\ +98-2537706694, Fax:+98-2537704233, E-mail: jafarbegloo_2004@yahoo.com
}

Received: December 10, 2013; Revised: December 19, 2014; Accepted: April 20, 2015

\begin{abstract}
Background: Some pregnant women discontinue iron supplements consumption due to Gastrointestinal (GI) complications, whereas pregnancy induces the same complications physiologically.

Objectives: The aim of the present study was to assess GI complications of ferrous sulfate in pregnant women.

Patients and Methods: This randomized, double-blind, placebo-controlled clinical trial was performed on 176 pregnant women referred to prenatal care clinic of Maryam Hospital from April 2011 to February 2012. Pregnant women with $\mathrm{Hb} \geq 13.2 \mathrm{gr} / \mathrm{dL}$ at $13^{\text {th }}-18^{\text {th }}$ weeks of gestation were selected based on the inclusion criteria and were randomly assigned to the ferrous sulfate and placebo groups. The ferrous sulfate group $(n=90)$ received a 50-mg ferrous sulfate tablet daily from the $20^{\text {th }}$ week to the end of pregnancy and the placebo group ( $\mathrm{n}$ $=89$ ) received one placebo tablet in the same way. All participants were visited twice at $24^{\text {th }}-28^{\text {th }}$ and $32^{\text {nd }}-36^{\text {th }}$ weeks to assess the GI complications as well as $\mathrm{Hb}$ level to determine the $\mathrm{Hb}$ changes in two groups. Chi-square test, t-test and Kolmogorov-Smirnov test were used to analyze the data. P value of $<0.05$ and confidence level of $95 \%$ were considered as statistically significant.

Results: None of the GI complications were significantly different between the ferrous sulfate and placebo groups at $24^{\text {th }}-28^{\text {th }}$ and $32^{\text {nd }}$ $-36^{\text {th }}$ weeks. Hemoglobin drop lower than $10.5 \mathrm{gr} / \mathrm{dL}$ at $24^{\text {th }}-28^{\text {th }}$ weeks or lower than $11 \mathrm{~g} / \mathrm{dL}$ at $32^{\text {nd }}-36^{\text {th }}$ weeks was not observed in any cases.

Conclusions: It can be concluded that GI complications in pregnant women using ferrous sulfate are mostly caused by physiologic changes of pregnancy rather than ferrous sulfate; therefore, it is not reasonable to stop using ferrous sulfate due to GI complications.
\end{abstract}

Keywords: Iron Supplement; Randomized Cotrolled Trial; Pregnant Women; Hemoglobin

\section{Background}

Iron deficiency anemia (IDA) is one of the most important problems of mothers and children especially in developing countries, because it is highly prevalent in pregnancy $(1,2)$ and is associated with some complications such as preterm birth $(3,4)$, low birth weight $(3,4)$, postpartum hemorrhage (3), decrease of iron storage in neonates (3) and small neonates for gestational age (4). Therefore, prevention and treatment of IDA is considered as a significant part of prenatal care.

Pregnant women need a large amount of iron, as in a single fetus pregnancy one gram of iron is required during pregnancy that is apparently more than the amount of iron storage in the body of most women. Also, the iron absorbed from food and iron stores are not sufficient to meet daily need of most pregnant women (5). Therefore, $30-60 \mathrm{mg} /$ day of iron is needed to prevent IDA in pregnant women with low risk of nutritional deficiency after the $20^{\text {th }}$ week of pregnancy (5-7).

Iron supplements may result in Gastrointestinal (GI) complications such as nausea, vomiting, diarrhea, consti- pation, heartburn and abdominal cramp in nonpregnant women $(3,8,9)$.

Some studies have shown that iron supplements during pregnancy developed some GI complications (e.g. nausea, vomiting, constipation and heartburn) (10-12); however, other studies have shown no complications (13). Furthermore, pregnancy induces some physiologic changes in the GI system that may cause the same foregoing complications (5).

Noncompliance of iron supplements due to GI complications may result in irregular consumption of iron supplements and prevents to achieve the goals of iron supplementation programs during pregnancy $(8,9)$.

A study by Hamidizade et al. (14) conducted during pregnancy and breastfeeding periods showed that $56.8 \%$ of participants used iron supplements irregularly and $10.2 \%$ did not use them at all, and that nausea and vomiting were the causes of irregular use of iron in $12.4 \%$ of participants.

Usually, pregnant women attribute GI complications to 
iron supplements rather than pregnancy changes and immediately stop taking tablets (14), whereas there are not enough controlled trials to compare GI complications of iron supplements with placebo.

\section{Objectives}

The aim of the present study was to assess GI complications of ferrous sulfate among pregnant women.

\section{Patients and Methods}

This randomized, double-blind, placebo-controlled clinical trial was performed on 176 pregnant women referred to nonreferral prenatal care clinic of general governmental Maryam Hospital in Tehran, Iran, from April 2011 to February 2012.

This study was approved by the ethics committee of Tarbiat Modarres University and all participants completed the informed consent form. Data were collected by a single observer and single laboratory.

Inclusion criteria were the age range of $17-35$ years, $\mathrm{Hb}$ $\geq 13.2 \mathrm{gr} / \mathrm{dL}$ between the onset of $13^{\text {th }}$ week and end of $18^{\text {th }}$ week, singleton pregnancy, pregestational Body Mass Index (BMI) of 19.8-26, having good nutrition, no smoking, no alcohol consumption, no drug addiction, with no diseases associated with polycythemia such as asthma and chronic hypertension, with no history of GI diseases such as peptic ulcer, reflux esophagitis, gastritis, GI bleeding, with no diseases resulting in nausea, vomiting, diarrhea, constipation, heartburn and abdominal pain before pregnancy, with no history of any systemic diseases or hyperemesis gravidarum in present pregnancy and no living in very high altitudes.

Some studies showed that in pregnant women with $\mathrm{Hb}$ $\geq 13.2 \mathrm{gr} / \mathrm{dL}$, lack of iron consumption did not result in anemia during pregnancy and after delivery but the consumption of iron increased the risk of low birth weight and preeclampsia (14); therefore, we incorporated the pregnant women with $\mathrm{Hb} \geq 13.2 \mathrm{gr} / \mathrm{dL}$ into the present study without worry about anemia in the placebo group.

Exclusion criteria were: termination of pregnancy before first and second visits for interviewing $\left(24^{\text {th }}-28^{\text {th }}\right.$ and $32^{\text {nd }}-36^{\text {th }}$ weeks), drop of serum Hb level below 10.5 $\mathrm{gr} / \mathrm{dL}$ in $24^{\text {th }}-28^{\text {th }}$ weeks or below $11 \mathrm{gr} / \mathrm{dL}$ in $32^{\text {nd }}-36^{\text {th }}$ weeks, bleeding due to any cause after inclusion time and taking other supplements including iron after the onset of the study.

The volume of sample was calculated 85 for each group based on a statistical power of $80 \%$ (total $n=170$ ). Sampling was purposeful and performed merely in outpatient prenatal care clinic of the hospital. A total of 2029 pregnant women were enrolled in the prenatal clinic from April 2011 to February 2012. Since we predicted that some participants might be excluded from the study somehow, we included 9 excess women in the study; so, 179 pregnant women with $\mathrm{Hb} \geq 13.2 \mathrm{gr} / \mathrm{dL}$ at $13^{\text {th }}-18^{\text {th }}$ weeks of gestation were selected on the basis of the in- clusion criteria. After completing the informed consent form and demographic questionnaire, they were randomly assigned to ferrous sulfate $(\mathrm{n}=90)$ and placebo $(\mathrm{n}=89)$ groups using simple randomization to achieve the most generalizability and external validity.

Three women were excluded due to consumption of additional supplement containing iron (one in the placebo group, two in the ferrous sulfate group).

Finally, the analysis was conducted on 88 women in each group (Figure 1).

The ferrous sulfate group $(n=90)$ received a 50-mg ferrous sulfate tablet daily from the $20^{\text {th }}$ week to the end of pregnancy and the placebo group $(n=89)$ received one placebo tablet in the same way. All participants were asked to take the tablet at bedtime and discontinue any other supplements containing iron or multivitamin after inclusion time. Gastrointestinal complications were asked and recorded in a checklist at visits of $24^{\text {th }}-28^{\text {th }}$ and $32^{\text {nd }}-36^{\text {th }}$ weeks. Some participants reported more than one complication and the researcher recorded all of them to be analyzed.

All participants were taught the components of an appropriate diet for pregnancy and were given a written sheet about a suitable diet based on Persian food and recommended daily allowance (RDA). In all remainder prenatal visits, the researcher asked some questions about the subjects' performance in preserving the trained diet, GI complications and tablet consumption.

Blood sampling for cell blood count (CBC) test was conducted three times on all cases of the both groups: the first one, at the onset of the study (at $13^{\text {th }}-18^{\text {th }}$ weeks) to select the participants and the other two times, after intervention at $24^{\text {th }}-28^{\text {th }}$ and $32^{\text {nd }}-36^{\text {th }}$ weeks of pregnancy to assess the trend of $\mathrm{Hb}$ and hematocrit changes. Hemoglobin drop lower than $10.5 \mathrm{gr} / \mathrm{dL}$ in the second trimester or lower than $11 \mathrm{gr} / \mathrm{dL}$ in the third trimester was defined as anemia (the Center for Disease Control and Prevention definition).

All CBC tests were conducted in a single laboratory using a single device (Sysmex K1000, Sysmex Corporation, Tokyo, Japan).

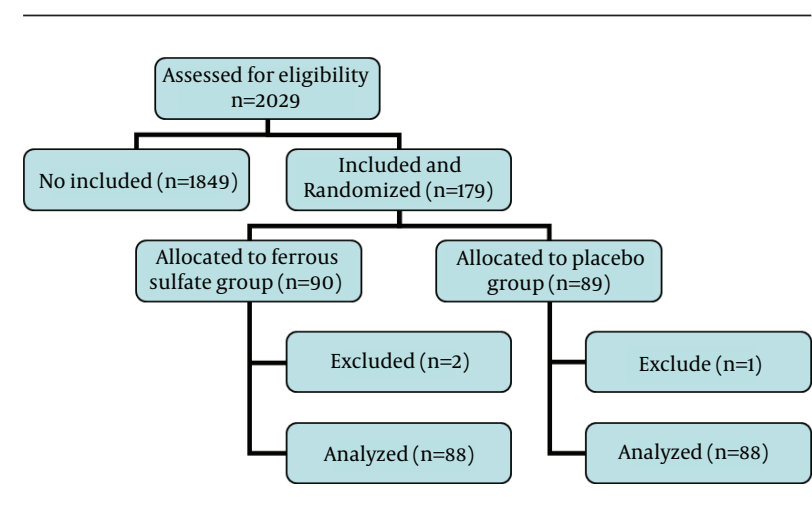

Figure 1. Flowchart of Sampling 
Both ferrous sulfate and placebo tablets were made by Modava Medication Company in Iran and packed in an identical way. The wrapping included a code known only to the main researcher who conducted the randomization. Neither the pregnant women nor the midwife/doctor prescribing the tablets knew the group allocations; so, the study was double-blind.

To compare the GI complications between the ferrous sulfate and placebo groups, chi-square test was used. The P value of $<0.05$ and confidence level of $95 \%$ were considered as statistically significant.

T-test was used to analyze age, gestational age, pregestational BMI and $\mathrm{Hb}$ because Kolmogorov-Smirnov test showed normal distribution of these variables. Gastrointestinal complications, occupation and educational level were analyzed using the chi-square test. Data were analyzed using SPSS version 14 (Chicago; IL). This study had been registered as an iranian registry of clinical trials number: IRCT 138807182558N1.

\section{Results}

A total of 179 pregnant women were included in the study. One subject in the placebo group and two subjects in the ferrous sulfate group were excluded.

The findings showed no significant difference between the two groups in age, pregestational BMI, educational levels, occupation and serum levels of $\mathrm{Hb}$ at the onset of the study using chi-square test and t-test (Table 1).

None of the GI complications were significantly different between the ferrous sulfate and placebo groups at $24^{\text {th }}-28^{\text {th }}$ and $32^{\text {nd }}-36^{\text {th }}$ weeks (Tables 2 and 3 ).

Hemoglobin drop lower than $10.5 \mathrm{gr} / \mathrm{dL}$ at $24^{\text {th }}-28^{\text {th }}$ weeks or lower than $11 \mathrm{gr} / \mathrm{dL}$ at $32^{\text {nd }}-36^{\text {th }}$ weeks was not observed in any cases.

\begin{tabular}{|c|c|c|c|}
\hline Variable & Ferrous-Sulfate Group & Placebo Group & P Value \\
\hline Age, $y^{b, c}$ & $26.62 \pm 4.51(17-35)$ & $25.72 \pm 4.1(17-35)$ & NS \\
\hline GA, wk $\mathbf{k}^{\mathbf{b}, \mathbf{c}}$ & $13.61 \pm 4.12$ & $13.89 \pm 14$ & NS \\
\hline Pregestational BMI b,c, $\mathrm{Kg} / \mathrm{m}^{2}$ & $23.43 \pm 2.93$ & $23.59 \pm 2.72$ & NS \\
\hline Educational levels ${ }^{d}$ & & & NS \\
\hline Primary school ${ }^{\mathrm{e}}$ & 10.8 & 8.2 & \\
\hline High school ${ }^{\mathrm{e}}$ & 75 & 81.3 & \\
\hline University ${ }^{\mathrm{e}}$ & 14.2 & 10.5 & \\
\hline Occupation d & & & NS \\
\hline Employee e & 10.1 & 11.3 & \\
\hline Housewife ${ }^{e}$ & 89.9 & 88.8 & \\
\hline$H b^{b, c}, g r / d L$ & $13.90 \pm 0.73$ & $14.01 \pm 0.79$ & NS \\
\hline
\end{tabular}

\footnotetext{
a Abbreviations: BMI, Body Mass Index; GA: Gestational Age; Hb, Hemoglobin; and NS, non-significant.

$\mathrm{b}$ The values presented as mean $\pm \mathrm{SD}$.

c T-test.

d Chi-square test.

e The values are presented as percent.
}

Table 2. Frequency Distribution of Gastrointestinal Complications of Ferrous Sulfate and Placebo at $24^{\text {th }}-28^{\text {th }}$ Weeks of Pregnancy $a, b$

\begin{tabular}{lccc}
\hline GI Complications & Ferrous Sulfate Group & Placebo Group & P Value $^{\mathbf{c}}$ \\
\hline Nausea & $2(2.3)$ & $2(3.9)$ & 0.575 \\
Vomiting & $0(0)$ & $1(2)$ & 0.187 \\
Diarrhea & $0(0)$ & $1(2)$ & 0.187 \\
Constipation & $4(4.5)$ & $2(3.2)$ & 0.364 \\
Loss of appetite & $0(0)$ & $0(0)$ & 0.158 \\
Heart burn & $3(3.4)$ & $1(2)$ & 0.623 \\
Abdominal pain & $0(0)$ & $1(2)$ & 0.187 \\
\hline
\end{tabular}

\footnotetext{
a Abbreviation: GI: gastrointestinal.

b The values are presented as No. (\%).

c Chi-square test.
} 
Jafarbegloo E et al.

\begin{tabular}{lccc}
\hline \begin{tabular}{l} 
Table 3. Frequency Distribution of Gastrointestinal Complications of Ferrous Sulfate and Placebo at $32^{\text {nd }}-36^{\text {th }}$ \\
\hline GI Complications
\end{tabular} & Ferrous Sulfate Group & Placebo Group & P Value $^{\text {b }}$ \\
\hline Nausea & $15(16.1)$ & $7(14)$ & 0.737 \\
Vomiting & $3(3.2)$ & $5(10)$ & 0.093 \\
Diarrhea & $0(0)$ & $1(2)$ & 0.171 \\
Constipation & $12(12.9)$ & $2(4)$ & 0.088 \\
Loss of appetite & $4(4.3)$ & $2(4)$ & 0.932 \\
Heart burn & $15(16.1)$ & $4(8)$ & 0.172 \\
\hline Abdominal pain & $2(2.2)$ & $0(0)$ & 0.296 \\
\hline
\end{tabular}

${ }^{\mathrm{a}}$ The values are presented as No. (\%)

b Chi-square test.

\section{Discussion}

It is a common belief that oral iron supplements have unpleasant GI side effects $(3,8,9)$. On the other hand, physiologic changes of pregnancy may result in GI complications (5); however, some pregnant women attribute thoroughly the complications to iron compounds and stop using them (14).

In the present study, GI complications of ferrous sulfate were not significantly different between the ferrous sulfate and placebo groups. However, in a research conducted by Hamidizade et al.(14) during pregnancy and breastfeeding periods, $56.8 \%$ of the participants used iron supplements irregularly and $10.2 \%$ used nothing at all. Nausea and vomiting were the causes of irregular use of iron in $12.4 \%$ of participants. Furthermore, in a study in Iran, Bondarianzadeh et al. showed that iron supplements caused nausea and vomiting in $10.8 \%$ of pregnant women (11).

Makrides et al. (15) conducted a randomized clinical trial similar to the present study in nonanemic pregnant women in that they assessed the effectiveness and tolerability of low dose iron. The study group received an iron supplement $20 \mathrm{mg} /$ day from $20^{\text {th }}$ week to the end of pregnancy and the placebo group received one placebo tablet daily in the same way. The findings of this study demonstrated that there were no significant differences in GI complications between the two groups $(\mathrm{P}<0.05)$. Although we used ferrous sulfate $50 \mathrm{mg} /$ day and they used an iron supplement $20 \mathrm{mg} /$ day, Makrides et al. (15) findings were consistent with our findings.

Milman et al.(13) conducted a randomized double-blind clinical trial aimed at assessing the GI side effects of iron prophylaxis with different doses of ferrous fumarate on 404 healthy pregnant women. The subjects were randomized to four groups taking ferrous fumarate in doses of $20(n=99), 40(n=100), 60(n=102)$ and $80(n=103)$ $\mathrm{mg} /$ day at bedtime from the $18^{\text {th }}$ week to delivery. Milman et al. (13) demonstrated that frequencies of GI symptoms were not significantly different in the four groups at $32^{\text {nd }}$ and $39^{\text {th }}$ weeks of gestation; so, they did not relate to the iron dose. They concluded that pregnant women should not give up using iron supplements due to the concern

of non-existing side effects. Although they used ferrous fumarate and we used ferrous sulfate, their findings are consistent with those of the present study. The advantage of the present study was that side effects of iron supplement had been assessed in comparison with placebo in pregnancy; therefore, we could show the role of physiologic changes of pregnancy on GI symptoms.

Makrides et al.(15) compared GI side effects of $20 \mathrm{mg}$ daily of iron supplement with placebo and we compared GI side effects of $50 \mathrm{mg}$ daily iron supplement with placebo. Both studies showed no significant differences between the iron supplement and placebo groups in GI side effects. Milman et al. (13) compared GI side effects of 20, 40, 60 and $80 \mathrm{mg} /$ day of ferrous fumarate without using placebo and showed no significant differences between various doses of iron in GI side effects. Considering the findings of the three above studies, it seems that using iron supplements up to $80 \mathrm{mg}$ /day does not result in GI side effects.

Casanueva et al. (12) in another study on 120 pregnant women assessed the effectiveness and safety of weekly usage of iron supplement in comparison with daily usage. The supplement contained $60 \mathrm{mg}$ ferrous sulfate, $200 \mu \mathrm{g}$ folic acid and $1 \mu \mathrm{g}$ vitamin B12. The daily usage group $(\mathrm{n}=$ $60)$ received one tablet a day and the weekly usage group $(n=60)$ received two tablets simultaneously once a week. According to the findings, nausea, vomiting, heartburn and constipation were significantly less frequent in the weekly usage group $(\mathrm{P}<0.05)$.

Young et al.(10) in a study assessed the effectiveness and safety of weekly usage of iron supplement in comparison with daily usage in pregnant women showed that GI complications of the iron supplement were more frequent in the daily usage group than the weekly usage group $(6 \%$ versus $17 \%)(\mathrm{P}<0.05)$.

The findings of the two studies by Casanueva et al. (12) and Young et al. (10)are in disagreement with our findings. This discrepancy in findings may be due to the use of folic acid, multivitamin and vitamin B12 along with iron in their studies as well as the difference in the methods of the studies. 
The privileges of the present study in comparison with other studies are: being double-blind, placebo-controlled and controlled diet.

While evidences demonstrate GI complications of ferrous sulfate tablet in nonpregnant people $(3,8,9)$, the findings of the present study indicated no significant difference in GI complications of ferrous sulfate tablet between the ferrous sulfate and placebo groups. We conclude that GI complications in pregnant women using ferrous sulfate are mostly caused by physiologic changes of pregnancy rather than the iron supplement; therefore, it is not reasonable to stop using ferrous sulfate due to GI complications and it is not logical to expect disappearing GI complications after stopping it.

As we know, there are not any randomized double-blind placebo-controlled clinical trials similar to the present study; thus, it is suggested to repeat similar studies.

\section{Acknowledgements}

This research is a part of a M.Sc. dissertation by the first author. The authors express their gratitude to the participants in the study and also to the midwives working at the prenatal clinic of Maryam Hospital.

\section{Authors' Contributions}

Study concept and design: Esmat Jafarbegloo and Hoda Ahmari Tehran. Analysis and interpretation of data: Esmat Jafarbegloo and Tahmineh Dadkhah Tehrani. Drafting of the manuscript: Esmat Jafarbegloo. Critical revision of the manuscript for important intellectual content: Esmat Jafarbegloo, Hoda Ahmari Tehran and Tahmineh Dadkhah Tehrani. Statistical analysis: Esmat Jafarbegloo and Tahmineh Dadkhah Tehrani.

\section{References}

1. Thomson CA, Stanaway JD, Neuhouser ML, Snetselaar LG, Ste- fanick ML, Arendell L, et al. Nutrient Intake and Anemia Risk in the Women's Health Initiative Observational Study. J Am Diet Assoc. 2011;111(4):532-41.

2. Christian P, Khatry SK, LeClerq SC, Dali SM. Effects of prenatal micronutrient supplementation on complications of labor and delivery and puerperal morbidity in rural Nepal. Int J Gynaecol Obstet. 2009;106(1):3-7.

3. Milman N. Oral Iron Prophylaxis in Pregnancy: Not Too Little and Not Too Much! JPregnancy. 2012;2012:1-8.

4. Yi SW, Han YJ, Ohrr H. Anemia before pregnancy and risk of preterm birth, low birth weight and small-for-gestational-age birth in Korean women. Eur J Clin Nutr. 2013;67(4):337-42.

5. Cunningham FG, Leveno KJ, Bloom SL, Hauth JC, Rose D, Spong C. Williams obstetrics. London: MC Graw-Hill;2010. pp.173-4.

6. Ladipo OA. Nutrition in pregnancy: mineral and vitamin supplements. Am J Clin Nutr. 2000;72(1 Suppl):280S-90S.

7. Marra MV, Boyar AP. Position of the American Dietetic Association: nutrient supplementation. JAm Diet Assoc. 2009;109(12):2073-85.

8. Kumar V, Abbas A, Fausto N, Mitchell R. Robbins basic pathology. (8thedn). Philadelphia, PA: Saunders. Elsevier; 2007.

9. Moulessehoul S, Demmouche A, Chafi Y, Benali M. [Effect of iron supplementation among pregnant women at mother-and-baby clinic of Sidi Bel Abbes, West Algeria]. Sante. 2004;14(1):21-9.

10. Young MW, Lupafya E, Kapenda E, Bobrow EA. The effectiveness of weekly iron supplementation in pregnant women of rural northern Malawi. Trop Doct. 2000;30(2):84-8.

11. Bondarianzadeh D, Siassi F, Omidvar N, Golestan B, Keighobadi $\mathrm{K}$. Low compliance with the iron supplementation program among pregnant women in the rural areas of Kerman district, I.R.Iran. Nutr Res. 1998;18(6):945-52.

12. Casanueva E, Viteri FE, Mares-Galindo M, Meza-Camacho C, Loria A, Schnaas L, et al. Weekly iron as a safe alternative to daily supplementation for nonanemic pregnant women. Arch Med Res. 2006;37(5):674-82.

13. Milman N, Bergholt T, Eriksen L, Byg KE, Graudal N, Pedersen P, et al. Iron prophylaxis during pregnancy - how much iron is needed? A randomized dose- response study of 20-80 mg ferrous iron daily in pregnant women. Acta Obstet Gynecol Scand. 2005;84(3):238-47.

14. Hamidizade S, Moghadasi J, Hosseinali M, Alavi A. Causes of irregular using of iron supplements in pregnants and lactating women reffering to Brojen health centers in 2005, [in Persian]. J Shahre Kord Unive. 2008;9:91-6.

15. Makrides M, Crowther CA, Gibson RA, Gibson RS, Skeaff CM. Efficacy and tolerability of low-dose iron supplements during pregnancy: a randomized controlled trial. Am J Clin Nutr. 2003;78(1):145-53. 